\section{Brain, Behavior and Evolution}

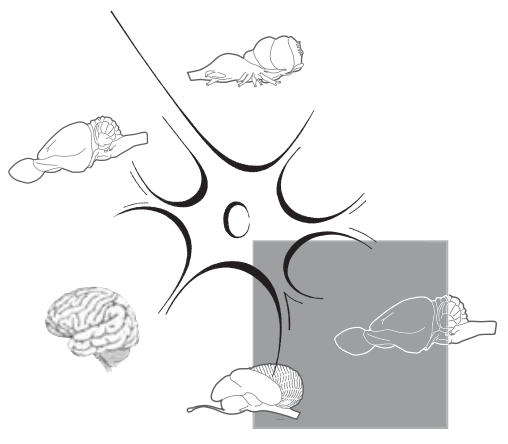

Brain Behav Evol 2014;83:177-180

DOI: $10.1159 / 000357551$
Published online: January 30, 2014

\title{
Is Dolphin Cognition Special?
}

\author{
Commentary on Manger PR (2013): Questioning the interpretations of \\ behavioral observations of cetaceans: is there really support for a special \\ intellectual status for this mammalian order? Neuroscience 250:664-696
}

\section{Onur Güntürkün}

Biopsychology, Faculty of Psychology, Ruhr University Bochum, Bochum, Germany

In 1969, Hodos and Campbell [1969] published a landmark paper with the title 'Scala naturae: why there is no theory in comparative psychology'. In it, the authors argued that many comparative psychologists of their time followed the concept of a continuous cognitive phylogenetic scale with diverse species ranked according to increasing levels of intelligence. This concept mostly rested on arbitrarily chosen behavioral tests whose outcomes were used to create ranks like 'goldfish - pigeon - rat cat - monkey - human'. Although these rankings seemed to have some face validity, this approach was full of problems and was in its essence unscientific. The most important problem was that slight changes in the experimental procedure could importantly alter the ranking, demonstrating that not cognitive but rather perceptual, motoric, or motivational limitations had determined the outcome. The paper of Hodos and Campbell [1969] marks the end of the scientific search for a general 'nonhuman IQ'.

Only for dolphins and chimps do some scientists still argue that there is sufficient evidence for their overall cognitive superiority to the extent that these species should be set apart from other nonhuman animals. In the case of dolphins, their arguments are usually two-fold: bottlenose dolphins (and other cetacean species) have very large and complex brains, recognize themselves in the mirror, use tools, have 'names', display some linguistic competences [Marino, 2004], and have self-awareness [Herman, 2012]. Due to these observations, some scientists even demand that dolphins no longer be kept in captivity [Marino and Frohoff, 2011]. These arguments have a political impact and countries like India have decided that 'cetaceans ... should be seen as "nonhuman persons" and as such should have their own specific rights'. But how strong is the scientific evidence for the cognitive exceptionality of dolphins? Manger and colleagues extensively reanalyzed the cortical [Manger, 2006] and hippocampal neuroanatomy of cetecea [Patzke et al., 2013] and came to radically different conclusions. In the last issue of Neuroscience, Manger [2013] also reviews the dolphin cognition literature and draws a quite sobering conclusion. But is his critique justified or does he throw the baby out with the bathwater?

Before going into the details, a relevant specification of the battlefield seems to be in order. Manger [2013] refers to 'cetaceans' in the title of his paper but the vast majority of references of behavioral studies are to bottlenose dolphins. The order of Cetacea contains two suborders: Mysticeti (baleen whales) and Odontoceti (toothed whales; dolphins are members of this suborder). In absolute terms, cetaceans have mostly large to very large brains with brain weights ranging between 164 and 7,181 g [Manger, 2006]. But the picture changes completely when looking at relative brain size (the brain weight proportional to the body weight) or the encephalization quotient (EQ; the relative brain weight of an animal compared to a baseline of relative brain weights of comparable species). The EQ of humans is slightly more than 7 and thus our brain is more than 7 times as large as expected for our mammalian body size [Jerison, 1973]. The EQ of cetaceans is extremely high for some Odontoceti like rough-toothed dolphins (EQ 4.95) [Marino, 2007] and extremely low for some Mysticeti like blue whales (EQ 0.16) [Manager, 2006]. The EQ was introduced by Jerison [1973] as a possible neural proxy for cognitive capacity. If we take the EQ seriously, we should abandon discussions on cetacean cognition in an overall manner since there is hardly any order of animals in which the EQ varies so widely. However, if we stick to absolute brain size, we also have to seriously discuss animals like elephants or pinnipeds [Manger et al., 2013]. Despite these inconsistencies, advocates [Marino et al., 2007] and critics [Manger, 2013] of the assumption of the superiority of 'cetacean

\section{KARGER}

E-Mail karger@karger.com

www.karger.com/bbe (c) 2014 S. Karger AG, Base

0006-8977/14/0833-0177\$39.50/0
Onur Güntürkün

Biopsychology, Faculty of Psychology

Ruhr University Bochum

DE-44780 Bochum (Germany)

E-Mail onur.guentuerkuen@ rub.de 
cognition' discuss them as a whole group. To avoid confusions of this kind, I will only discuss the cognition of the bottlenose dolphin, the species that was studied the most. Manger [2013] critically discusses close to 20 cognitive functions that range from awareness to vocal imitation. I will discuss just 4 of these faculties before trying a more general conclusion.

\section{Learning Artificial Means of Communication}

Dolphins live in a primarily acoustic world and use a variety of auditory signals for communication [Janik, 2013]. They use learned vocal labels to address each other [King and Janik, 2013], exchange signature whistles when meeting [Quick and Janik, 2012], and use their learned whistles in matching interactions in which an individual responds to a whistle of a conspecific by emitting the same whistle type [Janik, 2000]. Studies in captivity have even revealed a certain understanding of syntactic properties in sequences of sounds and gestures. Especially Louis Herman made an impressive scientific lifetime achievement in demonstrating that dolphins understand referential pointing [Herman et al., 1999], report the presence or absence of objects [Herman and Forestell, 1985], and understand imperative 'sentences' delivered in either acoustic or gestural format [Herman et al., 1984]. These 'sentences' consisted of units that represented objects, actions, agents, and modifiers. They could be combined by rules such that hundreds of different complex commands could be produced. Dolphins also seem to understand the identity of humans and their TV representations since they also followed gestures from video displays, although with some constraints [Herman et al., 1990].

These cognitive achievements are certainly highly impressive. But, as pointed out by Manger [2013], similar results could also be obtained from other species. Both chimpanzees [Premack, 1976] and bonobos [Savage-Rumbaugh et al., 1993] can learn and combine large numbers of symbols or gestures that stand for objects and actions. Chimpanzees produce functionally referential vocalizations which encode sufficient information about objects to allow conspecifics to respond accordingly [Slocombe and Zuberbühler, 2005]. Also a California sea lion quickly learned equivalence classes between symbols as a possible means for referential communication [Schusterman and Kastak, 1998]. Some dogs can not only learn the names of more than 200 different toys but also acquire new names by exclusion such that the dog attends to a new toy when hearing a novel word [Kaminski et al., 2004]. However, there is no evidence that dogs acquire syntactic rules. Also some parrots label and address conspecifics and the receivers primarily respond to calls that address themselves [Wanker et al., 2005; Balsby et al., 2012]. This is similar to the usage of whistles by dolphins to address other individuals [Janik, 2013; King and Janik, 2013]. Alex, possibly the most famous parrot ever, not only learned English words to referentially label many objects and their colors but also used short phrases and understood that the same object could be defined by material, color, shape, and object name [Pepperberg, 1999]. These data demonstrate that the ability to learn and to combine a large number of referential symbols and use them with a small set of syntactic rules [Kako, 1999] is within the reach of several nonhuman animals from the avian and mammalian classes. Bottlenose dolphins are not alone.

\section{Mirror Self-Recognition}

The claim of mirror-self-recognition in bottlenose dolphins [Reiss and Marino, 2001] was a turning point for discussions on dolphin cognition. Indeed, since the initial studies of Gallup [1970] in chimpanzees, the 'mark and mirror test' has been used as an indicator of self-recognition or even consciousness [Gallup, 1982]. It is therefore unfortunate that the study of Reiss and Marino [2001] has several shortcomings such that firm conclusions are difficult to draw. Harley [2013] listed them in length even before Manger [2013]. I will therefore only shortly summarize the main problems. The authors conducted two studies. In the first, one dolphin was marked, sham-marked, or not marked (control). Subsequently, the time spent with mark/sham-mark-directed behaviors in front of a reflective surface was measured. Unfortunately, in addition to the mirror, several walls with different degrees of reflective properties were available. Although the animal spent more time in front of the mirror when being marked, it also started to spend increasingly more time before the mirror in the sham-mark condi- tion after real marking trials had started. Thus, the control condition did not work properly. Due to these problems, the authors conducted a second study with two dolphins that had access to a smaller pool with one mirror as the sole reflective surface. Only the results of one dolphin are provided in detail; the results of the second one are shortly summarized. It is reported that this first animal swam especially fast towards the mirror location and spent more time there when being marked. This could indicate that the dolphin recognized itself and therefore tried to inspect the mark on its body. However, the depicted data pattern makes it likely that this overall effect was mostly due to higher mark-associated stays in the mirror location when the mirror was covered or even absent! In addition, critical testing of self-recognition requires that, during the availability of a visible mirror, significantly more mark-related behaviors be shown compared to a sham-marked condition. This was not tested. Manger [2013] in addition remarks, that due to the low acuity of dolphins, they should barely be able to see the marks. However, it is conceivable that the marks become more salient when the animal swims due to a form-from-motion effect.

The study of Reiss and Marino [2001] collected several intriguing hints for dolphin self-recognition but fell short of making a truly convincing case. Even if it had, we now know that, besides in humans, mirror-self-recognition has been shown not only in apes [Gallup, 1970; Lethmate and Dücker, 1973; Walraven et al., 1995] but also in Asian elephants [Plotnik et al., 2006] and magpies [Prior et al., 2008]. Thus, again several nonhuman animals from the avian and mammalian classes would reach this cognitive ability, with the bottlenose dolphin just being one of them.

\section{Numerical Concepts}

A very large number of animals can use numerosity, making it possible that numerical discrimination is a fundamental faculty of most animals [Dehaene, 1997]. Not surprisingly, dolphins have also been shown to solve discriminations based on numerosity [Kilian et al., 2003]. In a recent study, Yaman et al. [2012] went one step further and tested if bottlenose dolphins understand numerosity in an abstract way such that they understand that two given quantities can flexibly be integrated into a 
continuum of 'few' versus 'many'. To show this, the authors trained one dolphin to always choose the larger quantity of two diverse numerosities. Then, reversal training on a small subset of stimuli was conducted in which the dolphin had to choose the smaller quantity. After this training, the subject immediately started to choose the smaller quantities in novel and unreinforced combinations of other objects, showing that it had transferred the rule to new numerosity combinations. Manger [2013] posits that reversal learning was slow; he concludes that we should therefore doubt the conclusion about the cognitive flexibility of the dolphin in this task. But here he misses the point. It is not the length of the reversal training which is relevant (it often takes long) but rather the ability of the animal to directly generalize the reversed condition to subsequent new examples. This was given at a high level.

Again, we have an impressive cognitive feature in dolphins that resembles the results of another dolphin study in which the animals could categorize 'same' versus 'different' for different visual objects in an abstract manner [Mercado et al., 2000]. However, numerical competence at a level similar to that of the bottlenose dolphin has previously also been shown for chimps and grey parrots [Matsuzawa, 1985; Pepperberg, 1987].

\section{Tool Use}

In a population of dolphins in Shark Bay (Western Australia) a subgroup of animals plucks marine sponges from the seafloor and wears them over their rostra. They seem to use these sponges to probe the substrate for food [Krützen et al., 2005]. Sponging is biased to females, is transmit- ted in a matrilinial fashion, and does not seem to provide any obvious advantage to the sponging individual [Mann et al., 2008]. River dolphins in South America are also seen to sometimes carry sticks and clumps of grass, possibly as sexual displays [Martin et al., 2008]. Compared with these rather modest achievements, especially primates, parrots, and corvids show much more complex examples of tool use both in the wild and in the lab [McGrew, 2013]. To place this in the correct context, it is important to stress that many animals use tools, but only few make them to obtain food or use them as a weapon. In addition, the real cognitive challenge is not only to make tools but also to flexibly alter the sequence of actions during production or usage when being faced with novel challenges [Shumaker et al., 2011]. Up to now, only some primate [Fragaszy et al., 2013], parrot, and corvid species [Auersperg et al., 2011] have been shown to fulfill all of these criteria.

\section{Is Dolphin Cognition Special?}

The answer to this question is very clear and it is both 'no' and 'yes'. No, dolphin cognition is not exceptional since there is not a single achievement that has not also been shown in several other species. In some areas like learning of communicative signals, the data obtained in dolphins constitute one of the most remarkable examples of animal cognition [Herman et al., 1984]. In other areas like tool use, the cognitive abilities of dolphins are less outstanding or even modest when compared to those of primates, parrots, and corvids. Even a final proof for mirror self-recognition would not grant exceptionality to dolphins since they still would find themselves accompanied by apes, elephants, and magpies. However, in all major areas of comparative cognitive science dolphins have been shown to achieve fast learning, high flexibility, and a swift transfer of learned knowledge to new contingencies. So, dolphins are in many respects cognitive generalists, performing at an overall high level. We can conclude that the evolution of high cognitive skills has independently taken place in the suborder of Odontoceti, some members of the orders of Psittaciformes (parrots), the family of Corvidae, and the family of Hominidae. There seem to be many different routes to intelligence and possibly we have to add more groups of animals over the next decades.

Working in the field of animal behavior requires us to keep an emotional distance from the species that we study, even though this animal may be fascinating. Sometimes this distance is difficult to keep and scientists can draw unfounded conclusions about the cognitive exceptionality of some species. At this point, critics like Herbert Terrace [Terrace et al., 1979] in the field of chimp language, David Povinelli [Penn and Povinelli, 2007] for ape causal cognition, and Paul Manger [2013] on dolphin cognition play a very important role as advocatus diaboli for their field. They may sometimes overshoot with their critical interpretations, but without them we might be too easily swept away into an area where science and public expectations come too close.

\section{Acknowledgement}

I am grateful to Vincent Janik, Thomas Bugnyar, and Maik Stüttgen for their thoughtful comments.

\section{References}

-Auersperg AM, von Bayern AM, Gajdon GK, Huber L, Kacelnik A (2011): Flexibility in problem solving and tool use of kea and New Caledonian crows in a multi access box paradigm. PLoS One 6:e20231.

-Balsby TJS, Momberg JV, Dabelsteen T (2012): Vocal imitation in parrots allows addressing of specific individuals in a dynamic communication network. PLoS One 7:e49747.

Dehaene S (1997): The Number Sense: How the Mind Creates Mathematics. Oxford, Oxford University Press.
Fragaszy DM, Biro D, Eshchar Y, Humle T, Izar P, Resende B, Visalberghi E (2013): The fourth dimension of tool use: temporally enduring artefacts aid primates learning to use tools. Philos Trans R Soc Lond B Biol Sci 368: 20120410.

Gallup GG Jr (1970): Chimpanzees: self-recognition. Science 167:86-88.

Gallup GG Jr (1982): Self-awareness and the emergence of mind in primates. Am J Primatol 2:237-248.
Harley HE (2013): Consciousness in dolphins? A review of recent evidence. J Comp Physiol A Neuroethol Sens Neural Behav Physiol 199:565-582.

Herman LM (2012): Body and self in dolphins. Conscious Cogn 21:526-545.

-Herman LM, Abichandani SL, Elhajj AN, Herman EY, Sanchez JL, Pack AA (1999): Dolphins (Tursiops truncatus) comprehend the referential character of the human pointing gesture. J Comp Psychol 113:347-364. 
-Herman LM, Forestell PH (1985): Reporting presence or absence of named objects by a language-trained dolphin. Neurosci Biobehav Rev 9:667-681.

-Herman LM, Morrel-Samuels P, Pack AA (1990): Bottlenosed dolphin and human recognition of veridical and degraded video displays of an artificial gestural language. J Exp Psychol Gen 119:215-230.

-Herman LM, Richards DG, Wolz JP (1984): Comprehension of sentences by bottlenosed dolphins. Cognition 16:129-219.

Hodos W, Campbell CB (1969): Scala naturae: why there is no theory in comparative psychology. Psychol Rev 76:337-350.

- Janik BM (2000): Whistle matching in wild bottlenose dolphins (Tursiops truncatus). Science 289:1355-1357.

-Janik BM (2013): Cognitive skills in bottlenose dolphin communication. Trends Cogn Sci 17: 157-159.

Jerison H (1973): Evolution of the Brain and Intelligence. New York, Academic Press.

Kako E (1999): Elements of syntax in the systems of three language-trained animals. Anim Learn Behav 27:1-14.

Kaminski J, Call J, Fischer J (2004): Word learning in a domestic dog: evidence for 'fast mapping'. Science 304:1682-1683.

Kilian A, Yaman S, von Fersen L, Güntürkün O (2003): A bottlenose dolphin discriminates visual stimuli differing in numerosity. Learn Behav 31:133-142.

King SL, Janik VM (2013): Bottlenose dolphins can use learned vocal labels to address each other. Proc Natl Acad Sci USA 110:1321613221.

Krützen M, Mann J, Heithaus MR, Connor RC, Bejder L, Sherwin WB (2005): Cultural transmission of tool use in bottlenose dolphins. Proc Natl Acad Sci USA 102:8939-8943.

Lethmate J, Dücker G (1973): Untersuchungen zum Selbsterkennen im Spiegel bei OrangUtans und einigen anderen Affenarten. $\mathrm{Z}$ Tierpsychol 33:248-269.

Manger PR (2006): An examination of cetacean brain structure with a novel hypothesis correlating thermogenesis to the evolution of a big brain. Biol Rev 81:293-338.

-Manger PR (2013): Questioning the interpretations of behavioral observations of cetaceans: is there really support for a special intellectual status for this mammalian order? Neuroscience 250:664-696.
Manger PR, Spocter MA, Patzke N (2013): The evolutions of large brain size in mammals: the 'over-700-gram' club quartet. Brain Behav Evol 82:68-78.

Mann J, Sargeant BL, Watson-Capps JJ, Gibson QA, Heithaus MR, Connor RC, Patterson E (2008): Why do dolphins carry sponges? PLoS One 3:e3868.

Marino L (2004): Dolphin cognition. Curr Biol 14:R910-R911.

Marino L (2007): Cetacean brains: how aquatic are they? Anat Rec 290:694-700.

- Marino L, Connor RC, Fordyce RE, Herman LM, Hof PR, Lefebvre L, Lusseau D, McCowan B, Nimchinsky EA, Pack AA, Rendell L, Reidenberg JS, Reiss D, Uhen MD, Van der Gucht E, Whitehead H (2007): Cetaceans have complex brains for complex cognition. PLoS Biol 5:e139.

Marino L, Frohoff T (2011): Towards a new paradigm of non-captive research on cetacean cognition. PLoS One 6:e24121.

Martin AR, da Silva VM, Rothery P (2008): Object carrying as socio-sexual display in an aquatic mammal. Biol Lett 4:243-245.

Matsuzawa T (1985): Use of numbers by a chimpanzee. Nature 315:57-59.

McGrew WC (2013): Is primate tool use special? Chimpanzee and New Caledonian crow compared. Philos Trans R Soc Lond B Biol Sci 368: 20120422.

Mercado IE, Killebrew DA, Pack AA, Mácha IVB, Herman LM (2000): Generalization of same - different classification abilities in the bottlenosed dolphins. Behav Processes 50:7994.

Patzke N, Spocter MA, Karlsson KA, Bertelsen MF, Haagensen M, Chawana R, Streicher S, Kaswera C, Gilissen E, Alagaili AN, Mohammed OB, Reep RL, Bennett NC, Siegel JM, Ihunwo AO, Manger PR (2013): In contrast to many other mammals, cetaceans have relatively small hippocampi that appear to lack adult neurogenesis. Brain Struct Funct 2013, E-pub ahead of print.

Penn DC, Povinelli DJ (2007): Causal cognition in human and nonhuman animals: a comparative, critical review. Annu Rev Psychol 58: 97-118.
Pepperberg IM (1987): Evidence for conceptual quantitative abilities in the African grey parrot: labeling of cardinal sets. Ethology 75:3761.

Pepperberg IM (1999): The Alex Studies. Cambridge, Harvard University Press.

Plotnik JM, de Waal FBM, Reiss D (2006): Selfrecognition in an Asian elephant. Proc Natl Acad Sci USA 103:17053-17057.

Premack D (1976): Intelligence in Ape and Man. Mahwah, Erlbaum.

- Prior H, Schwarz A, Güntürkün O (2008): Mirror-induced behaviour in the magpie (Pica pica): evidence for self-recognition. PLoS Biol 6:e202.

Quick NJ, Janik VM (2012): Bottlenose dolphins exchange signature whistles when meeting at sea. Proc Biol Sci 279:2539-2545.

Reiss D, Marino L (2001): Mirror self-recognition in the bottlenose dolphin: a case of cognitive convergence. Proc Natl Acad Sci USA 98: 5937-5942.

-Savage-Rumbaugh ES, Murphy J, Sevcik RA, Brakke K, Williams S, Rumbaugh DM (1993): Language comprehension in ape and child. Monogr Soc Res Child Dev 58:1-222.

Schusterman RJ, Kastak D (1998): Functional equivalence in a California sea lion: relevance to animal social and communicative interactions. Anim Behav 55:1087-1095.

-Shumaker RW, Walkup KR, Beck BB (2011): Animal Tool Behavior, the Use and Manufacture of Tools by Animals. Baltimore, Johns Hopkins University Press.

-Slocombe S, Zuberbühler K (2005): Functionally referential communication in a chimpanzee. Curr Biol 15:1779-1784.

- Terrace HS, Petitto LA, Sanders RJ, Bever TG (1979): Can an ape create a sentence? Science 206:891-902.

-Walraven V, van Elsacker L, Verheyen R (1995): Reactions of a group of pygmy chimpanzees (Pan paniscus) to their mirror images: evidence of self-recognition. Primates 36:145150.

Wanker R, Sugama Y, Prinage S (2005): Vocal labelling of family members in spectacled parrotlets, Forpus conspicillatus. Anim Behav 70: 111-118.

- Yaman S, Kilian A, von Fersen L, Güntürkün O (2012): Evidence for a numerosity category that is based on abstract qualities of 'few' versus 'many' in the bottlenose dolphin (Tursiops truncatus). Front Psychol 3:473. 